\title{
Atrial contractility and fibrotic biomarkers are associated with atrial fibrillation after elective coronary artery bypass grafting
}

\author{
Constanze Bening, MD, ${ }^{\text {a,b }}$ Elena-Aura Mazalu, MD, ${ }^{\mathrm{a}}$ Jonathan Yaqub, MD, ${ }^{\mathrm{a}}$ Khaled Alhussini, MD, \\ Michal Glanowski, MD, ${ }^{\mathrm{a}}$ Tanja Kottmann, $\mathrm{MD},{ }^{\mathrm{c}}$ and Rainer Leyh, MD PhD ${ }^{\mathrm{a}, \mathrm{b}}$
}

\section{ABSTRACT}

Objective: New-onset postoperative atrial fibrillation is common after cardiac surgery. Less has been reported about the relationship among fibrosis, inflammation, calcium-induced left atrial and right atrial contractile forces, and postoperative atrial fibrillation. We sought to identify predictors of postoperative atrial fibrillation.

Methods: From August 2016 to February 2018, we evaluated 229 patients who had preoperative sinus rhythm before elective primary coronary artery bypass grafting. Of 229 patients, 191 maintained sinus rhythm postoperatively, whereas 38 patients developed atrial fibrillation. Preoperative tissue inhibitor of metalloproteinase-1, pentraxin-3, matrix metallopeptidase-9, galectin-3, highsensitivity C-reactive protein, growth differentiation factor 15 , and transforming growth factor- $\beta$ were measured. Clinical and echocardiographic findings (tricuspid annular plane systolic excursion for right heart function) and calcium-induced force measurements from left atrial and right atrial-derived skinned myocardial fibers were recorded.

Results: Patients with atrial fibrillation were older $(P=.001)$, had enlarged left atrial $(P=.0001)$ and right atrial areas $(P=.0001)$, and had decreased tricuspid annular plane systolic excursion $(P=.001)$. Levels of matrix metallopeptidase-9 and pentraxin-3 were decreased $(P<.05)$, whereas growth differentiation factor 15 was increased $(P=.001)$. We detected lower left atrial force values at calcium-induced force measurements $5.5(P<.05), 5.4(P<.01)$, and 5.3 to $4.52(P=.0001)$ and right atrial force values at calcium-induced force measurements 5.0 to $4.52(P<.05)$ in patients with postoperative atrial fibrillation. Multivariable analysis showed that advanced age $(P=.033)$, decreased left atrial force value at calcium-induced force measurement of $5.5(P=.033)$, enlarged left atrial $(P=.013)$ and right atrial $(P=.081)$ areas, and reduced tricuspid annular plane systolic excursion $(P=.010)$ independently predicted postoperative atrial fibrillation.

Conclusions: Advanced age, decreased left atrial force value at calcium-induced force measurement of 5.5, enlarged left atrial and right atrial areas, and reduced tricuspid annular plane systolic excursion were identified as independent predictors for postoperative atrial fibrillation. (J Thorac Cardiovasc Surg 2020;159:515-23)

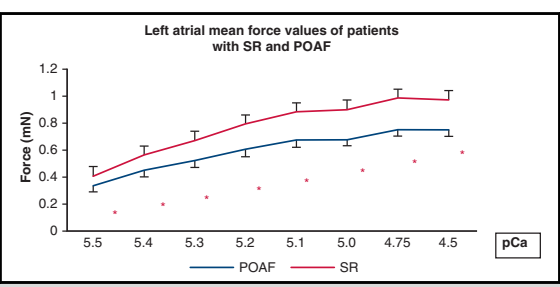

The $\mathrm{pCa}$ of intraoperative LAA-derived skinned myocardial fibers in 229 patients with preoperative SR undergoing elective primary CABG. Compared with patients who remained in $S R(n=191)$, patients with POAF $(\mathrm{n}=38$ ) had lower LA mean force (pCa 5.5 $[P<.05]$, pCa $5.4[P<.01]$, and pCa 5.3 to 4.52 $[P<.001])$. Multivariable analysis-identified decreased LA mean contractile force at $\mathrm{pCa} 5.5$ $(P<.05)$ independently predicted POAF. All values are given as mean \pm standard deviation.

\section{Central Message}

Patients with advanced age, enlarged RA and LA areas, and reduced TAPSE values representing reduced right heart function have an increased risk for POAF.

\section{Perspective}

POAF is associated with increased morbidity and mortality. Identifying risk factors for POAF may influence the management of patients at risk who are undergoing cardiac surgery and develop a preoperative targeted approach.

See Commentaries on pages 524 and 526.

\footnotetext{
From the a Department of Thoracic and Cardiovascular Surgery, University of Wuerzburg, Wuerzburg, Germany; ${ }^{b}$ Comprehensive Heart Failure Centre Würzburg, University of Wuerzburg, Wuerzburg, Germany; and ${ }^{\mathrm{c} C l i n i c a l}$ Research Organisation, Hamm, Germany.

This study received financial support by the Comprehensive Heart Failure Center Wuerzburg.

Institutional Review Board approval: 143/17-sc 6.10.2017
}

Received for publication June 6, 2018; revisions received Feb 14, 2019; accepted for publication Feb 15, 2019; available ahead of print March 28, 2019.

Address for reprints: Constanze Bening, MD, Department of Thoracic and Cardiovascular Surgery, University Hospital Wuerzburg Zentrum Operative Medizin, Oberduerrbacherstr, 6 97080, Wuerzburg, Germany (E-mail: Bening_C@ukw.de). $0022-5223 / \$ 36.00$

Copyright (c) 2019 by The American Association for Thoracic Surgery https://doi.org/10.1016/j.jtcvs.2019.02.068 


\begin{tabular}{|c|c|}
\hline \multicolumn{2}{|c|}{ Abbreviations and Acronyms } \\
\hline $\mathrm{AF}$ & $=$ atrial fibrillation \\
\hline CABG & $=$ coronary artery bypass grafting \\
\hline ELISA & $=$ enzyme-linked immunosorbent assay \\
\hline GDF-15 & $=$ growth differentiation factor 15 \\
\hline LA & $=$ left atrial \\
\hline LAA & $=$ left atrial appendage \\
\hline LVEF & $=$ left ventricular ejection fraction \\
\hline MMP-9 & $=$ matrix metalloproteinase 9 \\
\hline \multicolumn{2}{|c|}{$\begin{aligned} \text { NT-ProBNP } & =\text { N-terminal pro brain natriuretic } \\
\text { peptide } & \end{aligned}$} \\
\hline $\mathrm{pCa}$ & $=$ calcium-induced force measurement \\
\hline RA & $=$ right atrial \\
\hline RAA & $=$ right atrial appendage \\
\hline SR & $=$ sinus rhythm \\
\hline TAPSE & $\begin{aligned}= & \text { tricuspid annular plane systolic } \\
& \text { excursion }\end{aligned}$ \\
\hline TIMP-1 & $=\begin{array}{l}=\text { tissue inhibitor of metalloproteinase } \\
1\end{array}$ \\
\hline
\end{tabular}

$\checkmark$ Scanning this $\mathrm{QR}$ code will take you to the article title page to access supplementary information.

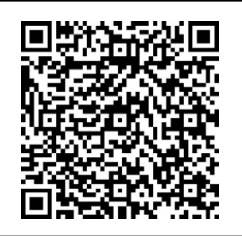

New-onset postoperative atrial fibrillation (POAF) is a common complication after cardiac surgery with an incidence of $10 \%$ to $65 \%$. $^{1-3}$ It is associated with poor short- and longterm outcomes, including increased risk for stroke and mortality. ${ }^{1-3}$ Advanced age has been described as an independent predictor of POAF. ${ }^{1}$ In patients at risk requiring coronary artery bypass grafting $(\mathrm{CABG})$, there is an unmet need of point-of-care predictors of POAF. ${ }^{2-4}$

Current understanding suggests that there is a highly interdependent metabolic, electrical, and contractile pathophysiology predominantly in atrial tissue. ${ }^{5-8}$ Rapid-rate arrhythmias are triggered because of the reduced availability of calcium. ${ }^{9-11}$

Some evidence suggests preexisting atrial fibrotic remodeling is present in some patients, which may lead to sustained conduction abnormalities. ${ }^{12}$ In persistent atrial fibrillation $(\mathrm{AF})$, potential mediators were oxidative stress, fibrosis, advanced age, inflammation, and pressure and volume overload. ${ }^{13-19}$ Recent work demonstrated the association of these mediators with specific biomarkers (eg, pentraxin 3, tissue inhibitor of metalloproteinase 1 [TIMP-1], matrix metalloproteinase 9 [MMP-9], high-sensitivity $C$-reactive protein, transforming growth factor- $\beta$, galectin-3, and growth differentiation factor 15 (GDF-15), ${ }^{10,11,20-23}$ but this link remains poorly characterized. It is plausible that inflammation induces POAF or that AF itself manifests inflammation and is merely a marker of increased risk. ${ }^{13-15}$ Similar inconsistencies exist regarding cardiac contractility. Although the impact of AF on cardiac contractility has been extensively investigated, the question of decreased preoperative contractility as a precondition for developing POAF remains underreported, especially in human tissue. Likewise, echocardiographic functional parameters such as tricuspid annular plane systolic excursion (TAPSE) for right heart function as a predictor of POAF remains unknown. Altogether, the relative paucity of articles and inconsistencies linking potential mechanisms inflammation, fibrosis, cardiac contractility, and right heart function with the development of POAF contributes to uncertainty.

In this study, we evaluated in detail the clinical, experimental, and echocardiographic data that predispose to the development of POAF in patients undergoing primary CABG procedures. We collected all clinical and experimental parameters (eg, blood samples and intraoperative specimens of resected left atrial appendages (LAAs) and right atrial appendages (RAAs). We analyzed the contractile properties of the left and right myofilaments of these patients and compared the results of patients who had postoperative sinus rhythm (SR) versus those with POAF.

\section{MATERIALS AND METHODS}

The present study is a prospective longitudinal cohort study examining consecutive patients with and without POAF. A total of 286 patients were initially planned to include in the study. Because of intraoperative contraindications, experimental problems, incomplete data, and denied permission to participate, we finally analyzed 229 patients with complete data sets. We included 229 patients in SR undergoing elective primary CABG between August 2016 and February 2018. A total of 191 patients maintained SR for the duration of the postoperative period, and 38 patients developed POAF (Figure 1).

All patients provided written informed consent. The Ethics Committee of the University Würzburg approved the study. All consented patients scheduled for elective, isolated CABG were included. All patients underwent on-pump CABG procedures and had resection of their LAA and RAA, which were then sent immediately to the laboratory for further investigation. We excluded patients with myocardial infarction within the previous 48 hours, patients with associated intracardiac procedures, emergency cases, patients with infectious diseases (eg, tuberculosis, human immunodeficiency virus, or hepatitis), patients with reoperations or minimally invasive procedures, or patients with incomplete data. We included all patients presenting in SR upon admission and excluded those with a history of AF (Figure 1).

Our registry contains retrospective preoperative and perioperative data modeled after the STS National Database criteria. ${ }^{24,25}$ Electrophysiologically documented AF and clinically diagnosed AF were included in the clinical documentation for the diagnosis of POAF and reported on the basis of the standardized definition established by the 2014 American Association for Thoracic Surgery guidelines ${ }^{24}$ and The Society of Thoracic Surgeons Practice guidelines and database. ${ }^{25}$ 


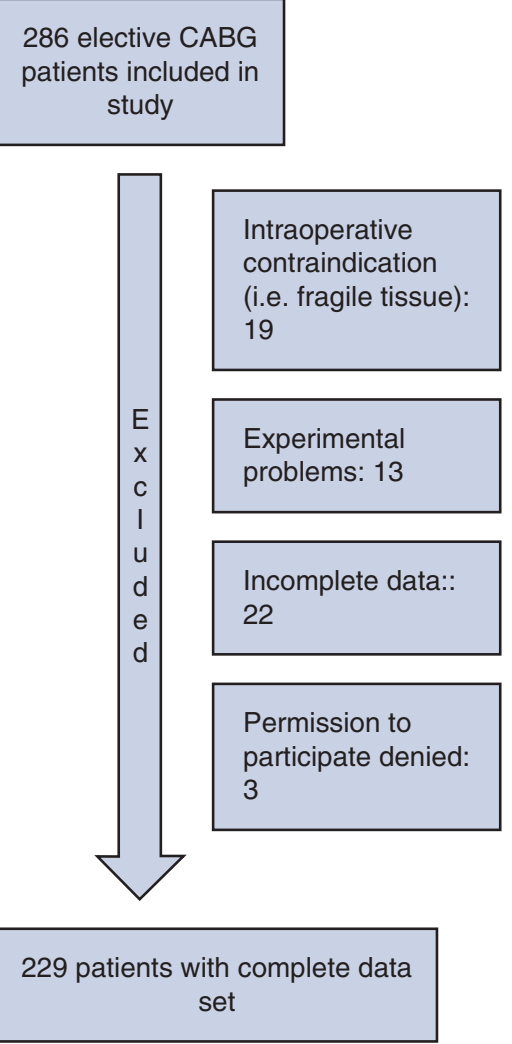

FIGURE 1. Consort diagram showing the reasons for excluding patients. $C A B G$, Coronary artery bypass grafting.

Accordingly, throughout the postoperative period, all patients were under continuous telemetric heart monitoring until discharge. Rhythm disturbances were detected and recorded in real-time. All patients had daily 12-lead electrocardiograms. Any type of POAF, including self-limiting or temporary, was recorded, and these patients were included in our study.

Preoperative blood samples were taken directly before induction of anesthesia in all patients. The samples were then immediately sent to the laboratory and stored at $-80^{\circ} \mathrm{C}$. Preoperative clinical chemistry included creatinine, glomerular filtration rate, and $\mathrm{N}$-terminal pro brain natriuretic peptide (NT-proBNP) (Roche Diagnostics, Mannheim, Germany). Left atrial (LA) tissue was examined via enzyme-linked immunosorbent assay (ELISA) for the following markers of fibrosis and inflammation: MMP9, TIMP-1, Galectin 3, GDF 15, and transforming growth factor- $\beta$ (Quantikine Elisa, DMP900, DTM100, DGAL30, DGD150, and DB100B, respectively, R\&D Systems, Bio-Techne, Wiesbaden, Germany), and high-sensitivity C-reactive protein (Cobas Integra 800). All ELISAs were conducted with the ELISA reader Tecan Infinity Pro (Tecan Group Ltd, Männedorf, Switzerland). Routine echocardiographic examinations were performed preoperatively and intraoperatively (Philips Epiq 7, Philips Health System, Hamburg, Germany). The echocardiographic examinations were performed by a trained medical assistant. The echocardiographic pictures were then seen and checked by 1 consultant for final approval. In the final analysis of our study, we reported and used the preoperative echocardiographic parameters. As a standard practice in our institution, to verify the completeness of LAA and RAA resection, we performed intraoperative echocardiography. LA and right atrial (RA) volumes and areas, left ventricular ejection fraction (LVEF), TAPSE, E/A, E/lat E, systolic pulmonary artery pressure, LA diameter, left ventricular diastolic diameter, V septal thickness, left ventricular posterior thickness, mitral valve deceleration time, E/med E, E', and E/E' were measured. The echocardiographic examinations were performed in accordance with the current guidelines of the

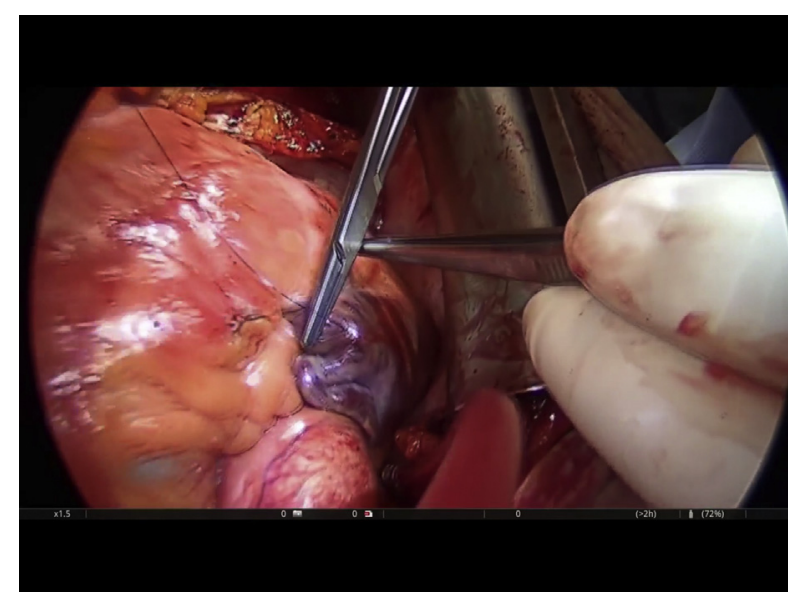

VIDEO 1. The resection of the RAA and LAA during CABG is shown, depicting the experimental procedure of pCa performed on our skinned fiber model. Video available at: https://www.jtcvs.org/article/S00225223(19)30515-X/fulltext.

American Society of Echocardiography. ${ }^{26,27}$ Intraoperative data and occurrence of POAF were documented for every patient.

\section{Experimental Set-up}

We measured the calcium-induced force of LA and RA skinned human fibers. The skinned fiber approach removes all membrane-dependent and receptor-mediated processes and excludes drug effects such as B-blocker.

All patients underwent careful LAA and RAA resections (Video 1). The RAA was resected for venous cannulation of extracorporeal circulation. The LAA was resected for stroke prevention immediately after aortic crossclamping and under cardioplegic arrest. All patients were operated on cardiopulmonary bypass using a single-clamp approach with antegrade Buckberg blood cardioplegia with an initial dose for 4 minutes and repetitive doses every 20 minutes for 2 minutes.

Samples were immediately placed in cold, oxygenated Krebs-Henseleit solution $\left(50 \mathrm{~mL}\right.$, amounts in mmol/L: $\mathrm{NaCl} 118,07, \mathrm{C}_{6} \mathrm{H}_{12} \mathrm{O}_{6}+\mathrm{H}_{2} \mathrm{O} 11,1$, $\mathrm{KCL} 4,7, \mathrm{NAHCO}_{3} 25, \mathrm{KH}_{2} \mathrm{PO}_{4} 1,2, \mathrm{MGSO}_{4} * 7 \mathrm{H}_{2} \mathrm{O} 1,2, \mathrm{CaCL}_{2} * 2 \mathrm{H}_{2} \mathrm{O}$ 1,8 ) with $30 \mathrm{mmol} / \mathrm{L} \mathrm{2,3}$ butanedione monoxime (BDM). BDM (Sigma Aldrich Chemie GmbH, Steinheim, Germany) is a myosin inhibitor that prevents contraction and minimizes cellular trauma during transport. In preparation for skinned fiber measurements, trabeculae were excised and exposed to a preparation solution containing Triton- $\mathrm{X}$ (amounts in $\mathrm{mmol} / \mathrm{L}: \quad \mathrm{C}_{3} \mathrm{H}_{4} \mathrm{~N}_{2} \quad 20, \quad \mathrm{NaN}_{3} \quad 10, \mathrm{C}_{14} \mathrm{H}_{24} \mathrm{~N}_{2} \mathrm{O}_{10} \quad 4, \quad \mathrm{C}_{4} \mathrm{H}_{10} \mathrm{O}_{2} \mathrm{~S}_{2} .2$, $\mathrm{MgCl}_{2} \times 6 \mathrm{H}_{2} \mathrm{O} 5, \mathrm{C}_{10} \mathrm{H}_{14} \mathrm{~N}_{5} \mathrm{O}_{13} \mathrm{P}_{3} \mathrm{Na}_{2} 5$, and $100 \mu \mathrm{L}$ Triton X (Sigma Aldrich Chemie $\mathrm{GmbH}$, Steinheim, Germany) for "skinning" of the sarcolemma, a process requiring 24 hours.

Next, the trabeculae were washed with freshly prepared solution (without Triton-X) followed by careful preparation of the fibers. The sarcolemma was removed, and single bundles $(0.3 \times 3 \mathrm{~mm})$ were isolated for calcium-induced force measurement (pCa). Both ends of the myofilaments were grasped with 2 forceps apart, of which 1 forcep is connected to a force transducer that recorded changes in the length of the suspended myofilaments in millinewtons. The fibers were then immersed in 12 varying calcium solutions, starting with the lowest calcium concentration. The filaments were lowered into the solution, avoiding any undue stretch. Changes in fiber length were recorded, and the fibers were subsequently prestretched in a relaxation solution (in mmol/ $\mathrm{L}: \mathrm{C}_{3} \mathrm{H}_{4} \mathrm{~N}_{2} 68.08$, $\mathrm{C}_{4} \mathrm{H}_{8} \mathrm{~N}_{3} \mathrm{O}_{5} \mathrm{PNa}_{2}+4 \mathrm{H}_{2} \mathrm{O}$ 327.2, $\mathrm{NaN}_{3}$ 65.01, $\mathrm{C}_{14} \mathrm{H}_{24} \mathrm{~N}_{2} \mathrm{O}_{10} 380.35$, $\mathrm{MgCl}_{2} * 6 \mathrm{H}_{2} \mathrm{O}$ 203.3, $\mathrm{C}_{4} \mathrm{H}_{10} \mathrm{O}_{2} \mathrm{~S}_{2} .154 .25$, and $\mathrm{C}_{10} \mathrm{H}_{14} \mathrm{~N}_{5} \mathrm{O}_{13} \mathrm{P}_{3} \quad \mathrm{Na}_{2}$ 551.1) to a sarcomere length of $2.0 \mu \mathrm{m}$. After achieving a prestretched steady state and adjusting the measurement curve to zero, the experimental 
TABLE 1. Characteristics of patients undergoing coronary artery bypass grafting

\begin{tabular}{|c|c|c|c|}
\hline Variable & Group 1 POAF $n=38$ & Group 2 SR n $=191$ & $P$ value \\
\hline Age (y) & $73.05 \pm 7.4$ & $67.53 \pm 9.81$ & .001 \\
\hline BMI & $29.25 \pm 4.40$ & $29.04 \pm 4.22$ & 6 \\
\hline Female gender; $\%(n)$ & $15.8(6)$ & $16.8(32)$ & .6 \\
\hline Male gender, \% (n) & $84.2(32)$ & $83.2(159)$ & 6 \\
\hline Hypertension; \% (n) & $84.2(32)$ & $74.8(143)$ & .04 \\
\hline $\mathrm{DM} ; \%(\mathrm{n})$ & $68.42(26)$ & $62.83(120)$ & .7 \\
\hline Preoperative creatinine $(\mathrm{mg} / \mathrm{dL})$ & $1.36 \pm 0.14$ & $1.09 \pm 0.47$ & .03 \\
\hline Preoperative GFR (MDRD) $\mathrm{mL} / \mathrm{min}$ & $67.24 \pm 22.82$ & $76.57 \pm 23.12$ & .02 \\
\hline Postoperative creatinine $(\mathrm{mg} / \mathrm{dL})$ & $1.24 \pm 0.88$ & $1.00 \pm 0.35$ & .03 \\
\hline Postoperative GFR (MDRD) $\mathrm{mL} / \mathrm{min}$ & $72.25 \pm 24.98$ & $84.07 \pm 25.29$ & .009 \\
\hline hs-CRP (pg/mL) & $0.655 \pm 0.18$ & $0.623 \pm 0.133$ & .6 \\
\hline HbAlc $(\%)$ & $6.23 \pm 1.08$ & $6.02 \pm 0.85$ & .2 \\
\hline Hyperlipoproteinemia \% (n) & $63(24)$ & $74(142)$ & .03 \\
\hline sPAP $(\mathrm{mm} \mathrm{Hg})$ & $33 \pm 11$ & $30 \pm 10$ & .4 \\
\hline LVEF $(\%)$ & $55.53 \pm 11.91$ & $54.45 \pm 9.06$ & .8 \\
\hline LA area $\left(\mathrm{cm}^{2}\right)$ & $27.88 \pm 7.21$ & $19.46 \pm 4.97$ & .0001 \\
\hline $\mathrm{RA}$ area $\left(\mathrm{cm}^{2}\right)$ & $21.84 \pm 8.76$ & $15.13 \pm 4.16$ & .0001 \\
\hline TAPSE & $18.61 \pm 3.85$ & $23.29 \pm 3.76$ & .001 \\
\hline E/Lat E' & $9.21 \pm 5.0$ & $8.64 \pm 4.18$ & .4 \\
\hline MV E/A & $1.85 \pm 0.20$ & $1.06 \pm 0.16$ & .07 \\
\hline MMP-9 (pg/mL) & $724.48 \pm 325.14$ & $875.68 \pm 375.78$ & .029 \\
\hline GDF-15 (pg/mL) & $1277.69 \pm 594.72$ & $1010.64 \pm 08.79$ & .001 \\
\hline Galectin $3(\mathrm{pg} / \mathrm{mL})$ & $10.35 \pm 4.28$ & $9.67 \pm 3.22$ & .3 \\
\hline TGF-ß (pg/mL) & $22.61 \pm 7.62$ & $32.94 \pm 8.66$ & .1 \\
\hline TIMP-1 (ng/mL) & $175.19 \pm 55.56$ & $164.77 \pm 37.36$ & .4 \\
\hline Pentraxin-3 (pg/mL) & $2419.80 \pm 663.11$ & $3135.33 \pm 204.03$ & .04 \\
\hline Preoperative NT-proBNP (pg/mL) & $1867.47 \pm 120.48$ & $1407.38 \pm 418.01$ & .0001 \\
\hline Preoperative CK (U/L) & $73 \pm 11$ & $96 \pm 15$ & .7 \\
\hline euroSCORE II & $2.59 \pm 0.47$ & $1.79 \pm 0.24$ & .8 \\
\hline
\end{tabular}

All values are given as mean \pm standard deviation or as a percentage (\%). $P O A F$, Postoperative atrial fibrillation; $S R$, sinus rhythm; $B M I$, body mass index; $D M$, diabetes mellitus; $G F R$, glomerular filtration rate; $M D R D$, Modification of Diet in Renal Disease; $h s-C R P$, high-sensitivity C-reactive protein; HbAlc, glycated hemoglobin Alc; sPAP, systolic pulmonary artery pressure; $L V E F$, left ventricular ejection fraction; $L A$, left atrium; $R A$, right atrium; TAPSE, tricuspid annular plane systolic excursion; $M V$, mitral valve; $M M P-9$, matrix metallopeptidase-9; GDF-15, growth differentiation factor-15;TGF- $\beta$, transforming growth factor $\beta ;$ TIMP-1, tissue inhibitor of metalloproteinases; $N T$-proBNP, $\mathrm{N}$ terminal pro brain natriuretic peptide; $C K$, creatinine kinase; euroSCORE, European System for Cardiac Operative Risk Evaluation.

cycle was repeated with ascending calcium concentrations. Fibers remained immersed in the calcium solutions for 15 minutes to achieve maximal forces at each calcium concentration. To move to the next calcium concentration, chloride dihydrate $\left(\mathrm{CaCl}_{2}+2 \mathrm{H}_{2} \mathrm{O}, 147.02 \mathrm{mN}\right)$ was added to the solution. Three myofilaments of every patient sample (LAA and RAA) were excised, and the experimental cycle was performed once with every fiber. The calcium concentrations $(\mathrm{pCa})$ are given as negative decadic logarithms, a dimensionless quantity. The calcium concentrations in ascending order were $\mathrm{pCa} 7.0,6.5,6.0,5.75,5.5,5.4,5.3,5.2,5.1,5.0$, 4.75 , and 4.52 . Concentrations ranging from $10^{-7}$ to $10^{-5} \mathrm{~mol} / \mathrm{L}$ are considered physiologic. Concentrations greater than $\mathrm{pCa} 5.0$ are supraphysiologic, but useful for eliciting maximal force capacity.

\section{Statistical Analysis}

Metric variables are given as means and medians, and the range of dispersion is given as standard deviations and quartiles. Categoric data are shown as absolute and relative frequencies. Metric data were tested for normal distribution with the Kolmogorov-Smirnov test. For testing pairs of independent and normally distributed variables, Student $t$ test was used. Before applying the $t$ test, the homogeneity of variances was ascertained with Levene's test. If homogeneity was not present, Welch's $t$ test was performed. Not normally distributed and independent variances were tested with the Mann-Whitney $U$ test. Normally distributed metric variables were analyzed with the Student $t$ test. All categoric variables were analyzed with the chi-square test and Fisher exact test. As a post hoc test, the standardized residuals were defined and interpreted as follows. Candidate variables considered for the multivariable analyses were those detected by univariate models as having a $P<.05$ or suggestive trend toward association $(P=.05-10)$ predictive of POAF; retention of variables in the multivariable model was set at $P<.05$. To discriminate independent risk factors, multivariable modeling was performed with methods of stepwise selection, with entry/stay criteria of $0.05 / 0.1$ using a likelihood-ratio test, with groups and candidate variables all competing for entry into a final 
TABLE 2. Intraoperative data in 229 patients

\begin{tabular}{lccc}
\hline \multicolumn{1}{c}{ Variable } & $\begin{array}{c}\text { Group 1 (POAF) } \\
\mathbf{n}=\mathbf{3 8}\end{array}$ & $\begin{array}{c}\text { Group 2 (SR) } \\
\mathbf{n = 1 9 1}\end{array}$ & $\boldsymbol{P}$ value \\
\hline $\begin{array}{c}\text { Aortic crossclamp } \\
\text { time (min) }\end{array}$ & $82.93 \pm 23.8$ & $76.86 \pm 29.13$ & .2 \\
Bypass time (min) & $114.11 \pm 41.08$ & $104.66 \pm 35.92$ & .07 \\
\hline No. of arterial grafts & $1.1 \pm 0.93$ & $1.60 \pm 0.86$ & .01 \\
No. of venous grafts & $1.08 \pm 1.05$ & $1.29 \pm 0.86$ & .1 \\
\hline
\end{tabular}

All values are given as mean \pm standard deviation. POAF, Postoperative atrial fibrillation; $S R$, sinus rhythm.

model predicting POAF. Univariate and multivariable analyses were performed in the same manner to identify predictors of POAF. We performed a 2-sided significance test for all tests. All estimates are provided with $95 \%$ confidence intervals. All diagrams were created with SPSS for Windows, Version 24 (SPSS Inc, Chicago, Ill).

\section{RESULTS}

Demographic data are depicted in Table 1. Patients with POAF were older ( $73 \pm 7$ years vs $68 \pm 10$ years, $P=.001$ ). The POAF group had a higher prevalence of arterial hypertension $(84 \%$ vs $75 \%, P=.04)$ and presented with higher preoperative creatinine $(1.36 \pm 0.14$ vs $1.09 \pm 0.47$, $P=.03)$ with decreased preoperative glomerular filtration rate $(67.2 \pm 22.82$ vs $76.57 \pm 23.12 \mathrm{~mL} / \mathrm{min}, P=.02)$. LA area was larger in patients with POAF (27.88 \pm $7.21 \mathrm{~cm}^{2}$ vs $19.46 \pm 4.97 \mathrm{~cm}^{2}, P=.0001$ ), as was RA area $\left(21.84 \pm 8.76 \mathrm{~cm}^{2}\right.$ vs $\left.15.13 \pm 4.16 \mathrm{~cm}^{2}, P=.0001\right)$. TAPSE was decreased in the POAF group $(18.61 \pm 3.85$ vs $23.29 \pm 3.76, P=.001)$. Regarding biomarkers for inflammation and fibrosis, MMP-9 was decreased in patients with POAF $(724.48 \pm 325.14 \mathrm{pg} / \mathrm{mL}$ vs $875.68 \pm 375.78 \mathrm{pg} / \mathrm{mL}, P=.029)$. Conversely, GDF-15 was increased in the POAF group (1277.69 \pm 594.72 vs $1010.64 \pm 1308.79, P=.001)$. Preoperative NT-proBNP was increased in patients with $\mathrm{AF}(1867.47 \pm 120.48$ vs $1407.38 \pm 4181.01, P=.0001)$. Pentraxin-3 was decreased in the POAF group $(2419.80 \pm 663.11$ vs $3135.33 \pm 204.03, P=.04$ ).

There were no statistically significant differences in the duration of the CABG procedure and in the number of venous grafts among patients (Table 2). The use of arterial grafts was lower among patients with POAF $(1.1 \pm 0.93$, $1.60 \pm 0.86, P=.01)$.

In LAA (Table 3 and Figures 2-4), we found lower force values in patients with POAF at the following calcium concentrations: pCa $5.5(0.34 \pm 0.19 \mathrm{mN}$ vs $0.41 \pm 0.23$ $\mathrm{mN}, P=.04)$, pCa $5.4(0.45 \pm 0.20$ vs $0.56 \pm 0.26 \mathrm{mN}$, $P=.008)$, pCa $5.3(0.52 \pm 0.22$ vs $0.67 \pm 0.29 \mathrm{mN}$, $P=.0001)$, pCa $5.2(0.60 \pm 0.24$ vs $0.79 \pm 0.33 \mathrm{mN}$, $P=.0001)$, pCa $5.1(0.67 \pm 0.25$ vs $0.88 \pm 0.35 \mathrm{mN}$, $P=.0001)$, pCa $5.0(0.68 \pm 0.27$ vs $0.90 \pm 0.37 \mathrm{mN}$, $P=.0001)$, pCa $4.75(0.75 \pm 0.28$ vs $0.98 \pm 0.38 \mathrm{mN}$, $P=.0001)$, and $\mathrm{pCa} 4.52(0.75 \pm 0.29 \mathrm{mN}$ vs
TABLE 3. Calcium-induced force values of left and right atrial myofilaments in 229 patients

\begin{tabular}{lccc}
\hline \multicolumn{1}{c}{ Variable } & $\begin{array}{c}\text { Group 1 } \\
(\text { POAF) } \mathbf{n}=\mathbf{3 8}\end{array}$ & $\begin{array}{c}\text { Group 2 (SR) } \\
\mathbf{n}=\mathbf{1 9 1}\end{array}$ & $\boldsymbol{P}$ value \\
\hline LAA pCa 5.5 & $0.34 \pm 0.19$ & $0.41 \pm 0.23$ & .04 \\
\hline LAA pCa 5.4 & $0.45 \pm 0.20$ & $0.56 \pm 0.26$ & .008 \\
\hline LAA pCa 5.3 & $0.52 \pm 0.22$ & $0.67 \pm 0.29$ & .0001 \\
\hline LAA pCa 5.2 & $0.60 \pm 0.24$ & $0.79 \pm 0.33$ & .0001 \\
LAA pCa 5.1 & $0.67 \pm 0.25$ & $0.88 \pm 0.35$ & .0001 \\
LAA pCa 5.0 & $0.68 \pm 0.27$ & $0.90 \pm 0.37$ & .0001 \\
LAA pCa 4.75 & $0.75 \pm 0.28$ & $0.98 \pm 0.38$ & .0001 \\
LAA pCa 4.52 & $0.75 \pm 0.29$ & $0.97 \pm 0.38$ & .0001 \\
RAA pCa 5.0 & $0.57 \pm 0.28$ & $0.68 \pm 0.32$ & .04 \\
RAA pCa 4.75 & $0.63 \pm 0.30$ & $0.76 \pm 0.34$ & .03 \\
RAA pCa 4.52 & $0.62 \pm 0.31$ & $0.75 \pm 0.26$ & .03 \\
\hline
\end{tabular}

All values are given as mean \pm standard deviation. $P O A F$, postoperative atrial fibrillation; $S R$, sinus rhythm; $L A A$, left atrial appendage; $p C a$, calcium concentration (negative decadic logarithm); $R A A$, right atrial appendage.

$0.97 \pm 0.38 \mathrm{mN}, P=.0001)$. Likewise, in RAA (Table 3), we found a trend toward reduced force values for patients with POAF at calcium concentrations of $\mathrm{pCa}$ $5.2(0.51 \pm 0.25$ vs $0.60 \pm 0.28 \mathrm{mN}, P=.07)$ and $\mathrm{pCa}$ $5.1(0.57 \pm 0.27 \mathrm{mN}$ vs $0.67 \pm 0.30 \mathrm{mN}, P=.062)$. The difference became significant between groups at $\mathrm{pCa}$ with reduced force values in patients with POAF: $\mathrm{pCa} 5.0$ $(0.57 \pm 0.28 \mathrm{mN}$ vs $0.68 \pm 0.32 \mathrm{mN}, P=.04), \mathrm{pCa} 4.75$ $(0.63 \pm 0.30$ vs $0.76 \pm 0.34 \mathrm{mN}, P=.03)$, and $\mathrm{pCa} 4.52$ $(0.62 \pm 0.31 \mathrm{mN}$ vs $0.75 \pm 0.26 \mathrm{mN}, P=.03)$.

Multivariable analysis revealed the following parameters as independent predictors for new-onset POAF after CABG: LAA force value at $\mathrm{pCa} 5.5(P=.033)$, LA area $(P=.013), \mathrm{RA}$ area $(P=.081)$, TAPSE $(P=.010)$, and advanced age $(P=.033)$ (Table 4$)$.

There was no in-hospital death. New-onset POAF occurred in 7 patients $(18 \%)$ on postoperative day 1 , increasing to 15 patients $(40 \%)$ on day 2 and 13 patients $(35 \%)$ on day 4 and decreasing to 3 patients (7\%) on day 5 . Length of stay was longer in the POAF group (13.23 days [median $11 \pm 3$ ] vs 10.87 days [median $10 \pm 2$ ]), but this difference was not significant (data not shown).

\section{DISCUSSION}

This study demonstrates that preoperative patients with SR who develop AF after CABG have significantly reduced preoperative contractile capacity in the LA and RA tissue as measured in the skinned fiber model (Figure 5). We chose the skinned fiber approach because the myocardial contractile apparatus is a valid surrogate for intrinsic myocardial function, independent of membrane-dependent processes and proteins. ${ }^{22,23}$

Previous work has proposed several pathophysiologic models of POAF, such as alterations in refractoriness or 
Left atrial mean force values of patients with SR and POAF

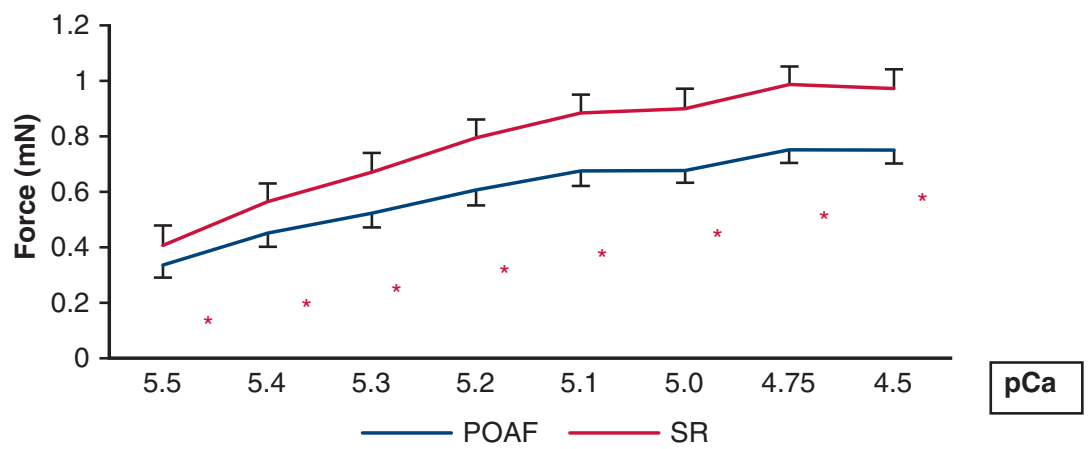

FIGURE 2. $\mathrm{pCa}$ of intraoperative LAA-derived skinned myocardial fibers in 229 patients with preoperative SR undergoing elective primary CABG. Compared with patients who remained in SR $(\mathrm{n}=191)$, patients with POAF $(\mathrm{n}=38)$ had lower LA mean force values $(\mathrm{pCa} 5.5[P<.05]$, $\mathrm{pCa} 5.4$ $[P<.01]$, and $\mathrm{pCa} 5.3$ to $4.52[P=.0001])$. Multivariable analysis identified decreased LA mean force values at pCa $5.5(P<.05)$ independently predicted POAF. All values are given as mean \pm standard deviation. $S R$, Sinus rhythm; $P O A F$, postoperative atrial fibrillation; $p C a$, calcium concentration (negative decadic logarithm).

local reentry pathways, probably caused by mechanisms of reperfusion injury, such as local inflammation and insufficient cardioplegic protection of the atria during cardiopulmonary bypass. Recent work has focused on atrial-specific mechanisms resulting in early contractile dysfunction and metabolic remodeling. Multiple studies

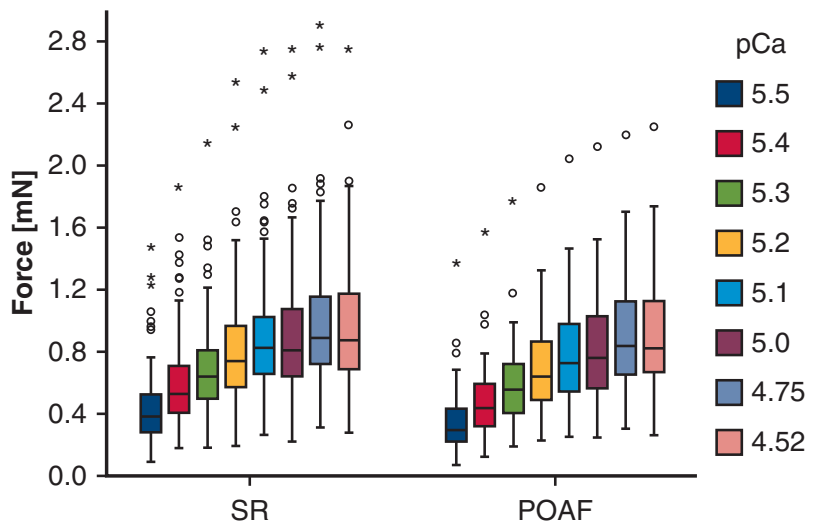

FIGURE 3. Box and whisker plots assessed the relationship between patients who remained in SR $(\mathrm{n}=191)$ and POAF $(\mathrm{n}=38)$ after primary $\mathrm{CABG}$ and $\mathrm{pCa}$. Postoperative patients in SR showed significantly higher force values when exposed to increasing calcium concentrations. Each plot encompasses 3 measurements for every patient based on increasing $\mathrm{pCa}$ for each variable ( $\mathrm{n}=573$ for postoperative SR per quartile; $\mathrm{n}=114$ for POAF per quartile). The upper and lower borders of the box represent the upper and lower quartiles. The middle horizontal line represents the median. The upper and lower whiskers represent the maximum and minimum values of nonoutliers. Circle (O) and asterisk (*) above the "whiskers" represent mild $(\mathrm{Q} 3+1.5$ [interquartile range] or extreme $(\mathrm{Q} 3+3$ [interquartile range]) outliers and observations, respectively, relative to the majority of force values. All values are given as mean \pm standard deviation. Force is given in $\mathrm{mN}$. $S R$, Sinus rhythm; $P O A F$, postoperative atrial fibrillation; $\mathrm{pCa}$, calcium concentration (negative decadic logarithm). have shown the negative impact of AF on atrial contraction, but the data are scant on the effect of new-onset $\mathrm{AF}$ in skinned human fibers. ${ }^{23,28,29}$ Reduced force capacity has been demonstrated histologically and on echocardiography solely for chronic and persistent $\mathrm{AF}^{29}$ However, there are no data linking new-onset $\mathrm{AF}$ and the 
TABLE 4. Independent predictors of postoperative atrial fibrillation

\begin{tabular}{lrrrr}
\hline & & \multicolumn{2}{c}{$\mathbf{9 5} \% \mathbf{C I}$} & \\
\cline { 3 - 4 } & OR & Lower & Upper & $\boldsymbol{P}$ value \\
\hline LAA 5.5 & & & & .033 \\
LAA 5.5 (1) & 0.01 & 0.01 & 1.577 & .101 \\
LAA 5.5 (2) & 12.00 & 1.32 & 108.98 & .027 \\
LAA 5.5 (3) & 0.38 & 0.03 & 4.518 & .444 \\
LA area & & & & .013 \\
LA area (1) & 0.19 & 0.01 & 6.39 & .360 \\
LA area (2) & 0.24 & 0.01 & 7.10 & .413 \\
LA area (3) & 5.63 & 0.30 & 103.75 & .244 \\
RA area & & & & .081 \\
RA area (1) & 0.00 & 0.00 & & .997 \\
RA area (2) & 72.00 & 2.43 & 2129.03 & .013 \\
RA area (3) & 88.04 & 2.77 & 2794.28 & .011 \\
TAPSE & & & & .010 \\
TAPSE (1) & 112.67 & 4.33 & 2929.09 & .004 \\
TAPSE (2) & 2.29 & 0.13 & 38.57 & .565 \\
TAPSE (3) & 5.87 & 0.24 & 139.31 & .273 \\
Age & & & & .033 \\
Age (1) & $0, .28$ & 0.23 & 3.55 & .329 \\
Age (2) & 11.54 & 1.11 & 119.87 & .040 \\
Age (3) & 7.712 & 0.59 & 100.25 & .119 \\
\hline Accinnnn
\end{tabular}

According to the 4 quartiles, the following ORs and CIs were calculated. $O R$, Odds ratio; $C I$, confidence interval; $L A A$, left atrial appendage; $L A$, left atrium; $R A$, right atrium; TAPSE, tricuspid annular plane systolic excursion.

cardiac contractile capacity of atrial myofilaments, partly due to inconsistent experimental techniques and measurements of functional parameters. ${ }^{23}$ Depressed force values are assumed to arise from the downregulation of L-type $\mathrm{Ca}^{2+}$ channels and increased $\mathrm{Ca}^{2+}$ influx via sodiumcalcium exchangers. The resultant reduction of maximal force recruitment and impaired calcium sensitivity seem to be related to new-onset $\mathrm{AF}^{30-32}$ Force values are reportedly reduced by approximately $70 \%$ compared with patients in SR. ${ }^{30,31}$ These prior observations corroborate with our results. However, these studies do not differentiate between left and right myofilament function. We observed a significant reduction of force values in cardiac myofilaments of both sides of the heart. Likewise, Belus and colleagues ${ }^{29}$ observed significant reductions in maximal tension rates, passive tension, and increased calcium sensitivity in chronic AF. Other studies report comparable results in chronic AF, usually with small sample sizes and in RA or LA tissue, but not both. ${ }^{30,31}$

We also observed significant differences in the serum levels of preoperative MMP-9, GDF-15, pentraxin-3, and NT-proBNP. On multivariable analysis, these biomarkers did not influence the risk of POAF (Table 4 and Figure 5). Previous work revealed that MMP-9 is increased in patients with ischemic heart disease and associated with vascular remodeling and atherosclerotic plaque formation. ${ }^{33}$ Other studies showed that increased levels of TIMP-1, an

\section{Consort Flow diagram:}

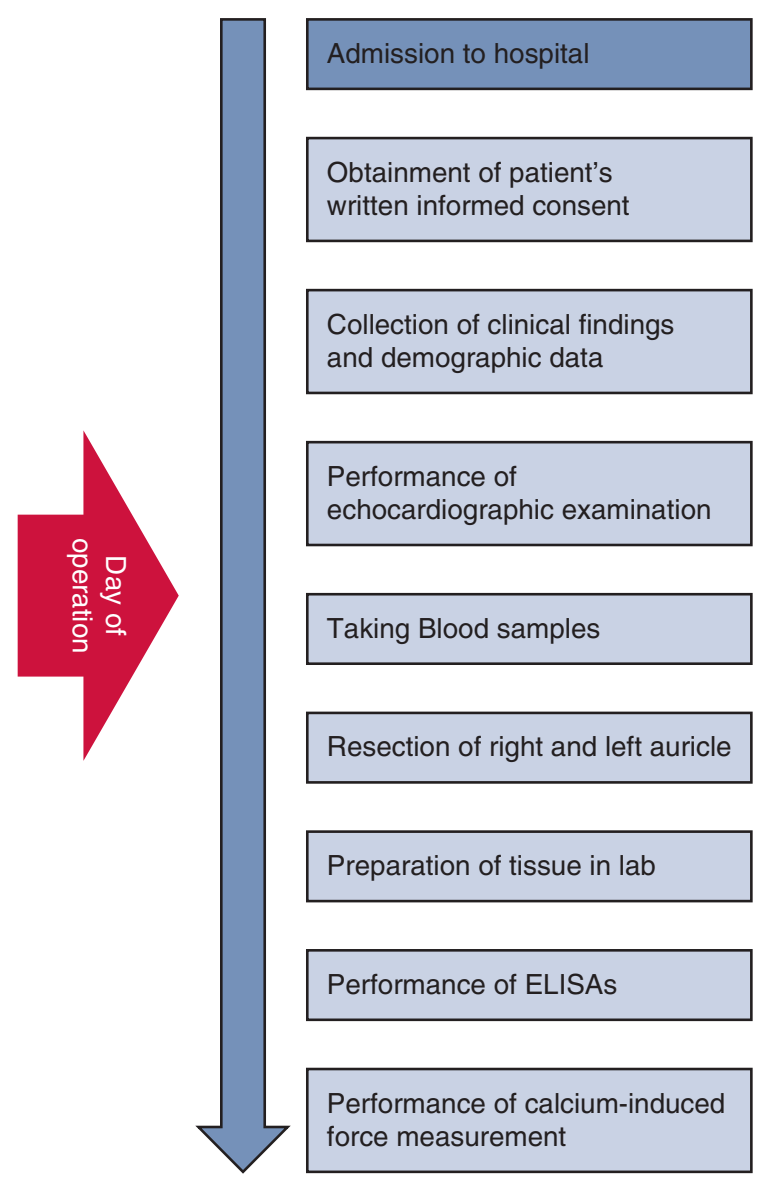

FIGURE 5. Consort flow diagram of the time work flow of the operative and experimental procedures. ELISA, Enzyme-linked immunosorbent assay.

important inhibitory regulator of MMPs, MMP-9, and NT-proBNP are associated with the development and progression of $\mathrm{AF}^{34}$ MMP-9 as an inflammatory biomarker is also strongly associated with hypertension and renal disease. ${ }^{35}$ Likewise, in our experience with patients with POAF, we observed decreased MMP-9 levels. In those patients, we also found higher prevalence for arterial hypertension, decreased renal function and increased TIMP-1 levels (Table 1). The latter may have contributed to the decreased MMP-9 levels.

Other studies showed that GDF-15 is a strong predictor for mortality in patients with $\mathrm{AF}^{36}$ GDF-15 has been described as a marker of cellular stress, senescence, and inflammation, whereas NT-proBNP is known to signify myocardiocyte stress and dysfunction. ${ }^{37,38}$ Considerable data have shown that age is a strong predictor for $\mathrm{AF}^{39}$ Our POAF study population was older and had elevated levels of NT-proBNP.

The LA has so far been supposed to predict AF recurrence in patients after catheter ablation, ${ }^{40}$ and most recently 
also identified as a potential predictor for POAF $^{41}$ This work supports our observation of increased LA area in patients developing AF.

On echocardiography, we found significantly reduced TAPSE values in patients with POAF with AF. This is an important finding, considering that current guidelines are virtually silent on the effects of $\mathrm{AF}$ in echocardiographic assessment of right heart function. ${ }^{42} \mathrm{AF}$, in our observation, has a definite impact on TAPSE as a measure of right ventricular systolic function compared with patients with SR. ${ }^{43}$ This is plausible, because AF and right ventricular dysfunction frequently coexist in heart failure with preserved ejection fraction and AF is strongly associated with reduced RA and right ventricular function. ${ }^{44}$ We found significantly reduced force values at higher calcium concentrations in RA fibers. This was equally true for supraphysiologic calcium concentrations and corresponds to the assumption that contractile reserve is reduced in patients with $\mathrm{AF}$ (Figure 5).

A novel and surprising finding was the enlarged RA area in patients with POAF. RA area index was recently identified as a strong independent predictor of hospitalization due to clinically significant supraventricular arrhythmias in patients with pulmonary hypertension. ${ }^{45}$ However, there exists no information about the predictive value of RA area in patients with $\mathrm{AF}$ (without pulmonary hypertension). Our binary regression analysis shows that RA area is an independent predictor for POAF. From a clinical standpoint, closer attention to echocardiographic parameters such as atrial areas or TAPSE in patients undergoing elective CABG procedure may be warranted. Of note, but of less practical importance, we also identified an experimental parameter capable of independently predicting the newonset POAF. We observed that the force value of LA tissue at a calcium concentration (pCa) of 5.5 was significantly decreased in patients with AF. Of note, this is a relatively low calcium concentration, representing a baseline state of the myofilament before calcium levels increase and trigger contraction (Figure 5). To our knowledge, this has not been described in the literature.

The observation of significantly reduced experimental force values in patients with POAF, combined with the clinical finding of normal LVEF on echocardiogram, suggests that patients with experimentally observed decreased contractile function are predisposed for the development of POAF despite having normal LVEF. These findings might help identify surgical cardiac patients at risk for POAF. Patients presenting with enlarged LA and RA areas, reduced TAPSE, and advanced age are at higher risk for developing POAF and might benefit from closer surveillance in the postoperative course or from high potassium or magnesium levels, preventing the occurrence of POAF. Further studies need to confirm our observations in larger cohorts.

\section{Study Limitations}

Several limitations of this study must be noted. First, 286 patients undergoing elective CABG were initially screened for participation in our study, but 229 patients were finally enrolled with complete clinical and experimental data sets. Excluded patients were those with intraoperative contraindications of atrial resection, such as fragile tissues $(\mathrm{n}=19)$, incomplete data $(\mathrm{n}=20)$, withdrawn consent $(\mathrm{n}=3)$, and tissues with technical problems during experimentation $(\mathrm{n}=13)$. Although complete medical histories were collected, prior sporadic episodes of AF in these patients cannot be completely excluded. Although to date, this study is one of the largest of its kind, the sample size is still inadequate to draw meaningful conclusions. Untoward influences of other clinical parameters, such as the higher prevalence of arterial hypertension in the AF group or larger atrial sizes, are always possible and might affect contractility values. Furthermore, operator-specific treatment of the tissue samples with possible damage to the trabeculae cannot be excluded, although harvesting protocols were designed with a high degree of standardization. Some of our results seem to conflict with the current understanding, such as increased MMP-9 and pentraxin-3 values in the SR group, and must be reevaluated in a larger population. Despite the nature of our study, our initial observations may serve as a catalyst for future mechanistic and randomized prospective studies examining our hypothesis.

\section{CONCLUSIONS}

In preoperative patients with SR who develop $\mathrm{AF}$ after elective CABG, LA and RA contractility are significantly reduced compared with patients without POAF. The force value of LA myofilaments at $\mathrm{pCa}$ of 5.5 appeared to be an independent predictor for the development of POAF. Several other independent parameters seem relevant to predict the development of AF: advanced age, LA area, RA area, and TAPSE.

\section{Conflict of Interest Statement}

Authors have nothing to disclose with regard to commercial support.

\section{References}

1. Filardo G, Damiano RJ Jr, Ailawadi G, Thourani VH, Pollock BD, Sass DM, et al. Epidemiology of new-onset AF following coronary artery bypass graft surgery. Heart. 2018;10:985-92.

2. Filardo G, Ailawadi G, Pollock BD, da Graca B, Sass DM, Phan TK, et al. Sex differences in the epidemiology of new-onset in-hospital post-coronary artery bypass graft surgery AF: a large multicenter study. Circ Cardiovasc Qual Outcomes. 2016;9:723-30.

3. Pollock BD, Filardo G, da Graca B, Phan TK, Ailawadi G, Thourani V, et al. Predicting new-onset post-coronary artery bypass graft AF with existing risk scores. Ann Thorac Surg. 2018;105:115-21.

4. Hwang HY, Park S, Kim HK, Kim YJ, Kim KB. Early restoration of atrial contractility after new-onset AF in off-pump coronary revascularization. Ann Thorac Surg. 2013;95:520-4. 
5. Mariscalco G, Engelström KG, Ferrarese S, Cozzi G, Bruno VD, Sessa F, et al. Relationship between atrial histopathology and AF after coronary artery bypass surgery. J Thorac Cardiovasc Surg. 2006;13:1364-72.

6. Page PL, Hassanalizadeh H, Cardinal R. Transitions among AF, atrial flutter and sinus rhythm during procainamide infusions and vagal stimulation in dogs with sterile pericarditis. Can J Physiol Pharmacol. 1991;69:5-24.

7. Sideris DA, Toumanidis ST, Tselepatiotis E, Kostopoulos K, Stringli T, Kitsiou T, et al. Atrial pressure and experimental AF. Pacing Clin Electrophysiol. 1995;18:1679-85.

8. Vardas PE, Vemmos K, Sideris DA. Susceptibility of the left and right atria to fibrillation in hyperglycemia and hypoglycemia. J Electrocardiol. 1993;26: 147-53.

9. Kazui T, Henn MC, Watanabe Y, Kovacs SJ, Lawrance CP, Greenberg JW, et al. The impact of 6 weeks of AF on left atrial and ventricular structure and function. J Thorac Cardiovasc Surg. 2015;150:1602-8.

10. Wu G, Wang S, Cheng M, Peng B, Liang J, Huang H, et al. The serum matrix metalloproteinase-9 level is an independent predictor of recurrence after ablation of persistent AF. Clinics. 2016;71:251-60.

11. Narducci ML, Pelargonio G, Rio T, Leo M, Di Monaco A, Musaico F, et al. Predictors of postoperative $\mathrm{AF}$ in patients with coronary artery disease undergoing cardiopulmonary bypass: a possible role for myocardial ischemia and atrial inflammation. J Cardiothorac Vasc Anesth. 2014;28:512-9.

12. Adeniran I, MacIver D, Garratt C, Ye J, Hancox J, Zhang H. Effects of persistent AF-induced electrical remodeling on atrial electro-mechanics - insights from a 3D model of the human atria. PLoS One. 2015;10:e142397.

13. den Uijl DW, Cabanelas N, Benito EM, Figueras R, Alarcón F, Borràs R, et al. Impact of left atrial volume, sphericity and fibrosis on the outcome of catheter ablation for AF. J Cardiovasc Electrophysiol. 2018;29:740-6.

14. Hansen BJ, Zhao J, Fedorov VV. Fibrosis and AF: computerized and optical mapping; a view into the human atria at submillimeter resolution. JACC Clin Electrophysiol. 2017;3:531-46.

15. Luo T, Chang CX, Zhou X, Gu SK, Jiang TM, Li YM. Characterization of atrial histopathological and electrophysiological changes in a mouse model of aging. Int J Mol Med. 2013;31:138-46.

16. Van Wagoner DR. Oxidative stress and inflammation in AF: role in pathogenesis and potential as a therapeutic target. J Cardiovasc Pharmacol. 2008;52:306-13.

17. Friedrichs $\mathrm{K}$, Klinke A, Baldus S. Inflammatory pathways underlying AF. Trends Mol Med. 2011;17:556-63.

18. Goldberger JJ, Arora R, Green D, Greenland P, Lee DC, Lloyd-Jones DM, et al. Evaluating the atrial myopathy underlying AF: identifying the arrhythmogenic and thrombogenic substrate. Circulation. 2015;132:278-91.

19. Engelmann M, Svendsen J. Inflammation in the genesis and perpetuation of AF. Eur Heart J. 2005;26:2083-92.

20. Soeki T, Bando S, Uematsu E, Matsuura T, Niki T, Ise T, et al. Pentraxin 3 is a local inflammatory marker in AF. Heart Vessels. 2014;29:653-8.

21. Roldán V, Marín F, Blann AD, García A, Marco P, Sogorb F, et al. Interleukin-6, endothelial activation and thrombogenesis in chronic AF. Eur Heart J. 2003;24:1373-80.

22. Corradi D. AF from the pathologist's perspective. Cardiovasc Pathol. 2014;23: 71-84.

23. Brandenburg S, Arakel EC, Schwappach B, Lehnart SE. The molecular and functional identities of atrial cardiomyocytes in health and disease. Biochim Biophys Acta. 2016;1863:1882-93.

24. Frendl G, Sodickson AC, Chung MK, Waldo AL, Gersh BJ, Tisdale JE, et al; American Association for Thoracic Surgery. 2014 AATS guidelines for the prevention and management of perioperative atrial fibrillation and flutter for thoracic surgical procedures. Executive summary. J Thorac Cardiovasc Surg. 2014;148:772-91.

25. Fernando HC, Jaklitsch MT, Walsh GL, Tisdale JE, Bridges CD, Mitchell JD, et al. The Society of Thoracic Surgeons practice guideline on the prophylaxis and management of atrial fibrillation associated with general thoracic surgery: executive summary. Ann Thorac Surg. 2011;92:1144-52.

26. Rudski LG, Lai WW, Afilalo J, Hua L, Handschumacher MD, Chandrasekaran K, et al. Guidelines for the echocardiographic assessment of the right heart in adults: a report from the American Society of Echocardiography endorsed by the European Association of Echocardiography, a registered branch of the European Society of Cardiology, and the Canadian Society of Echocardiography. J Am Soc Echocardiogr. 2010;23:685-713.

27. Lang RM, Badano LP, Mor-Avi V, Afilalo J, Armstrong A, Ernande L, et al. Recommendations for cardiac chamber quantification by echocardiography in adults: an update from the American Society of Echocardiography and the European Association of Cardiovascular Imaging. Eur Heart J Cardiovasc Imaging. 2015; 16:233-70.

28. Akella AB, Ding XL, Cheng R, Gulati J. Diminished $\mathrm{Ca}^{++}$sensitivity of skinned cardiac muscle contractility coincident with troponin T-band shifts in the diabetic rat. Circ Res. 1995;76:600-6.

29. Belus A, Piroddi N, Ferrantini C, Tesi C, Cazorla O, Toniolo L, et al. Effect of chronic AF on active and passive force generation in human trial myofibrils. Circ Res. 2010;107:144-52

30. Gasparovic H, Cikes M, Kopjar T, Hlupic L, Velagic V, Milicic D, et al. Atrial apoptosis and fibrosis adversely affect atrial conduit, reservoir and contractile function. Interact Cardiovasc Thorac Surg. 2014;19:223-30.

31. Ross Agner BF, Katz MG, Williams ZR, Dixen U, Jensen GB, Schwarz KQ. Left ventricular systolic function assessed by global longitudinal strain is impaired in AF compared to sinus rhythm. J Atr Fibrillation. 2017;10:1437.

32. El-Armouche A, Boknik P, Eschenhagen T, Carrier L, Knaut M, Ravens U, et al Molecular determinants of altered $\mathrm{Ca}^{2+}$ handling in human chronic AF. Circula tion. 2006;114:670-80.

33. Yu Q, Li H, Li L, Wang S, Wu Y. Correlation between genetic polymorphism of matrix metalloproteinase- 9 in patients with coronary artery disease and cardiac remodeling. Pak J Med Sci. 2015;31:648-53.

34. Stanciu AE, Vatasescu RG, Stanciu MM, Serdarevic N, Dorobantu M. The role of pro-fibrotic biomarkers in paroxysmal and persistent AF. Cytokine. 2018 103:63-8.

35. Xu TY, Zhang Y, Li Y, Zhu DL, Gao PJ. The association of serum inflammatory biomarkers with chronic kidney disease in hypertensive patients. Ren Fail. 2014 36:666-72.

36. Huxley R, Lopez F, Mac Lehose R, Eckfeldt J, Couper D, Leiendecker-Foster C, et al. Novel association between plasma matrix metalloproteinase- 9 and risk of incident $\mathrm{AF}$ in a case-cohort study: the atherosclerosis risk in communities studies. PLoS One. 2013;8:e59052.

37. Wang KF, Huang PH, Chiang CH, Hsu CY, Leu HB, Chen JW, et al. Usefulness of plasma matrix metalloproteinase-9 level in predicting future coronary revascularization in patients after acute myocardial infarction. Coron Artery Dis. 2013;24: 23-8.

38. Lewkowicz J, Knapp M, Tankiewicz-Kwedlo A, Sawicki R, Kamińska M, Waszkiewicz E, et al. MMP-9 in atrial remodeling in patients with AF. Ann Cardiol Angiol. 2015;64:285-91.

39. Hijazi Z, Oldgren J, Lindbäck J, Alexander JH, Connolly SJ, Eikelboom JW et al; ARISTOTLE and RE-LY Investigators. A biomarker-based risk score to predict death in patients with $\mathrm{AF}$ : the $\mathrm{ABC}$ (age, biomarkers, clinical history) death risk score. Eur Heart J. 2018;39:477-85.

40. Hijazi Z, Wallentin L, Siegbahn A, Andersson U, Christersson C, Ezekowitz J, et al. N-terminal pro-B-type natriuretic peptide for risk assessment in patients with AF: insights from the ARISTOTLE Trial (apixaban for the prevention of stroke in subjects with AF). J Am Coll Cardiol. 2013;61:2274-84.

41. Wallentin L, Hijazi Z, Andersson U, Alexander JH, De Caterina R, Hanna M, et al; ARISTOTLE Investigators. Growth differentiation factor 15, a marker of oxidative stress and inflammation, for risk assessment in patients with AF: insights from the apixaban for reduction in stroke and other thromboembolic events in AF (ARISTOTLE) trial. Circulation. 2014;130:1847-58.

42. Aksu U, Gulcu O, Aksakal E, Topcu S, Sevimli S, Tanboga IH. Comparison of the three conventional methods for the postoperative AF prediction. Echocardiogra phy. 2017:34:831-4.

43. Torii Y, Kusunose K, Yamada H, Nishio S, Hirata Y, Amano R, et al. Comparison of tricuspid annular plane systolic excursion in patients with AF versus sinus rhythm. Am J Cardiol. 2016;117:226-32.

44. Gorter TM, van Melle JP, Rienstra M, Borlaug BA, Hummel YM, van Gelder IC Right heart dysfunction in heart failure with preserved ejection fraction: the impact of AF. J Card Fail. 2018;24:177-85.

45. Waligóra M, Tyrka A, Miszalski-Jamka T, Urbańczyk-Zawadzka M, Podolec P, Kopeć G. Right atrium enlargement predicts clinically significant supraventricular arrhythmia in patients with pulmonary arterial hypertension. Heart Lung. 2018;47:237-42.

Key Words: skinned fiber method, postoperative new onset atrial fibrillation, $\mathrm{pCa}$ 